\title{
THE 16 MV TANDEM OF THE LABORATORI NAZIONALI DI LEGNARO
}

\author{
C. SIGNORINI \\ Istituto di Fisica dell'Università and INFN, Padova, \\ Laboratori Nazionali di Legnaro, Padova, Italy
}

\begin{abstract}
Résumé. - Un accélérateur Van de Graaff Tandem de $16 \mathrm{MV}$ est en construction au Laboratoire National de Legnaro près de Padoue. La machine équipée de deux Laddertrons horizontaux, sera utilisée pour un programme de recherche en physique nucléaire. Des courants élevés d'ions lourds sont prévus, jusqu'à $0,25 \mathrm{p} \mu \mathrm{A}$ en chlore et $0,10 \mathrm{p} \mu \mathrm{A}$ en iode à $16 \mathrm{MV}$.

Un injecteur avec une résolution en masse élevée (mieux que 1 pour 100) sera également installé. Cette installation est prévue pour fonctionner en 1980.

\footnotetext{
Abstract. - A 16 MV Tandem Van de Graaff accelerator is under construction at the Laboratori Nazionali di Legnaro near Padova.

The machine, equiped with two horizontal Laddertron charging systems, will be used for a nuclear physics research program.

High currents of heavy ion beams are planed : up to $0.25 \mathrm{p} \mu \mathrm{A}$ of chlorine and $0.10 \mathrm{p} \mu \mathrm{A}$ of iodine at $16 \mathrm{MV}$.

An injector with high mass resolution (better than 1 over 100) will also be installed.

This facility is expected to be in full operation early 1980 .
}

1. Introduction. - The idea of an electrostatic Tandem Van de Graaff accelerator at the Laboratori Nazionali di Legnaro (LNL), near Padova (Italy) was born few years after the installation, in the early 60 's, of the single ended CN 5.5 MeV Van de Graaff accelerator.

This idea concretized in 1966 with the proposal [1] for a $10 \mathrm{MV}$-MP Tandem. After several problems and strong fluctuations of the hope of the real feasibility of the project in 1974 a new proposal [2] for a 14 to $20 \mathrm{MV}$ Tandem was submitted and in the late autumn 1975 the INFN (Istituto Nazionale di Fisica Nucleare) placed the order of the 16 MV XTU Tandem at High Voltage Engineering Co. (HVEC - Burlington, Mass. USA) and decided to install it at his national laboratory placed in Legnaro.

The chief responsible of the project is Prof. R.A. Ricci (also director of LNL) who is leading a team of INFN researchers and technicians, and of researchers of several Universities (Padova, Milano, etc.), associated to the scientific programs of the INFN.

Once in full operation the new Tandem laboratory will be a facility open to all Italian physicists working in the field of pure and applied nuclear physics as well as in nuclear physics interdisciplinary fields.

The laboratory is expected to start in full operation around end 1979 beginning 1980.

This talk wants to be a presentation of the project with some comments on its most critical points. The present status of the project with the first results on the tests on some parts of the equipment will also be given.

2. The accelerator facility. -2.1 . GENERAL CONSIDERATIONS. - The whole accelerator system, including injector, tank and $90^{\circ}$ magnet analyzer, will be manufacted under responsibility of HVEC. In particular the injector will be constructed by General Ionex Co. (Ipswich, Mass. USA) and the accelerator tank by Belleli Industrie Meccaniche S.p.A. (Mantova, Italy).

A broad range of particles from $A=1$ (Hydrogen) up to $A>127$ (iodine) is supposed to be accelerated with currents above $100 \mathrm{nA}$ (particle) up to $16 \mathrm{MV}$ terminal voltage for the researches programs connected with the Tandem accelerator itself as well as with the Tandem + superconductive Cyclotron postaccelerator planed for the future (see the last part of the report).

2.2. The XTU TANDeM MACHINE. - The most important parameters and specifications of the XTUTandem are given in Table $I$.

The structure of the machine is very similar to that one of the upgraded - MP Tandem (always from HVEC, with $13 \mathrm{MV}$ guaranteed specifications).

The column will be that one of the XTU Tandem originally constructed at Burlington and tested without tubes up to $21 \mathrm{MV}$ (rated voltage $20 \mathrm{MV}$ ).

The tank length will be the same of the MP machine $(81 \mathrm{ft}=24.2 \mathrm{~m})$ plus two feet (total length $82 \mathrm{ft}=25.00 \mathrm{~m}$ ); but the tank diameter will be consi- 
Terminal voltage range without tubes

Terminal voltage range with tubes

Analyzed protons

Analyzed iodine

Analyzed chlorine

Terminal voltage stability

Totale charging current with laddertron
0-20 MV

0-16 MV

$5 \mu \mathrm{A}$ at $3 \mathrm{MV}$

$10 \mu \mathrm{A}$ at $7.5 \mathrm{MV}$

$5 \mu \mathrm{A}$ at $16 \mathrm{MV}$

$0.1 \mathrm{p} \mu \mathrm{A}$ at $16 \mathrm{MV}$

(most probable charge state)

$0.25 \mathrm{p \mu A}$ at $16 \mathrm{MV}$

(most probable charge state)

$50 \%$ transmission with

$0.25 \mu \mathrm{A}$ injected

$\pm 1.5 \mathrm{kV}$

$800 \mu \mathrm{A}$ derably bigger $25 \mathrm{ft}(=7.6 \mathrm{~m})$ instead of $18 \mathrm{ft}$ $(=5.5 \mathrm{~m})$.

The insulating gas will be pure $\mathrm{SF}_{6}$ at a pressure of 91 psi $(6.4 \mathrm{~atm})$ for a total weight of $\sim 37 \mathrm{t}$ to be stored in liquid phase during all the tank opening for servicing or repairing of the machine. The $\mathrm{SF}_{6}$ gas storing system, of conventional type, delivered also by HVEC has as main components two $150 \mathrm{HP}$ non lube compressors. A Kiney pump is supplied to evacuate the tank up to $\sim 100$ torr. The total turn around time tank opening + closing is estimated around $24 \mathrm{~h}$.

The basis vacuum will be guaranteed by two large 10 " oil (polyphenil aether) diffusion pumps at the low and high-energy end of the machine. The pumps have a freon refrigerator: cold cap plus a liquid nitrogen trap.

The vacuum seals inside the machine will be metallic. Following the positive experience in the last MP installations (i.e. Strasbourg) aluminium coated Helicoflex gaskets will be adopted. Outside the tank ordinary viton o-rings will be used.

The structure of the high voltage terminal housing is represented in figure 1 . The terminal spinning is

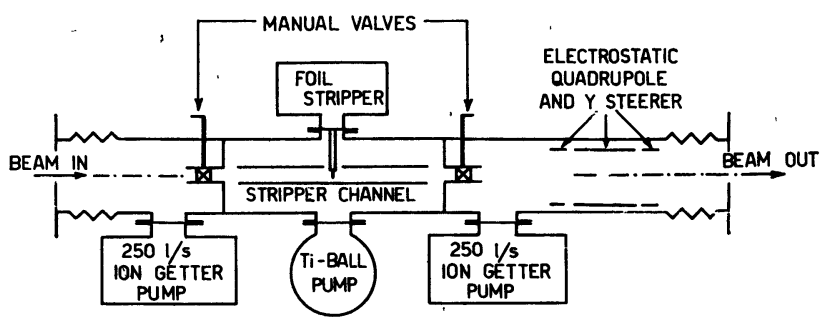

FIG. 1. - Lay out of the XTU Tandem high voltage terminal.

made by a structure which completely encloses the terminal region instead of the longitudinal bars adopted in the standard MP installations. The terminal is 10 feet long $(3.0 \mathrm{~m})$ and 81 inches $(206 \mathrm{~cm})$ in diameter. Power is provided by an insulating rotating shaft and terminal generator developing $6 \mathrm{~kW}$.

Two ion getter pumps (250 l/s - by Aerovac) will be placed at the two extremities in order to improve the vacuum conditions in the accelerating tubes.

The stripping system includes a $43.3^{\prime \prime}$ long $(1.10 \mathrm{~m})$ $34 "(\sim 9 \mathrm{~mm})$ diameter gas tube plus a 120 position foil chain mounted in such a way that the foils are positionable in the middle of the stripping channel.

The flow of the stripping gas is handled by a Titanium sublimation pump (4 Ti-ball ${ }^{\mathrm{TM}}$ sublimators by Varian inside a container below the stripping channel) and small aperture at both ends of the stripping channel.

The terminal houses also a 4-pole electrostatic triplett powered in such a way to have also some vertical steering features.

The acceleration tubes are 8 ( 4 each side), 14" diameter, with stainless steel inclined field electrodes and small apertures $11 / 8^{\prime \prime}(2.85 \mathrm{~cm})$ vertical times $5 "$ $(12.70 \mathrm{~cm})$ horizontal.

Each tube has 72 glass insulator 1 " thick and 73 electrodes; the $1^{\text {rst }}$ and the $73^{\text {rd }}$ electrodes are against terminations. The tube gradient is $56 \mathrm{kV} /$ in (= column gradient).

The XTU Tandem will have pratically the same tubes installed in the upgraded MP (were the guaranteed performances of $13 \mathrm{MV}$ are well reached). The only difference is that the MP installations two pairs of electrodes for each tube section are short circuited because of the MP column structure while in the XTU this does not appear. The extrapolation of the voltage holding capability of these tubes up to $16 \mathrm{MV}$ is based on the test at Burlington in spring 1973 (discussed in detail in reference [3]. Were the following beam species were analyzed: protons $0.5 \mu \mathrm{A}, 50 \%$ transmission, at $16 \mathrm{MV}$, oxygen $0.23 \mathrm{p} \mu \mathrm{A}, 30-40 \%$ transmission $\left(6^{+}\right.$state analyzed, most probable charge state with solid stripper) at $14 \mathrm{MV}$ and iodine $0.13 \mathrm{p \mu A}, 10$ $20 \%$ transmission $\left(6^{+}\right.$state analyzed, gas stripper) at $13 \mathrm{MV}$

The voltage divider system will be of mixed type.

The tube sections $1,2,3$ and $6,7,8$ will have a unique voltage divider located on the column: the 
equipotential planes of the column and the tubes ( 1 " distance) are connected.

The tube sections 4 and 5, the most critical because next to the high voltage terminal will have two separate dividers along the column and along the tubes connected only on the dead sections.

In this way column and tubes are somehow decoupled independently behaving so that small discharches along one will not effect the others. The advantages of this system, which has in itself the disadvantage of a bigger cost and complexity are extensively discussed in reference [4] and are summarized in the following:

a) reduction in the energy available for individual conditioning processes (microdischarges),

b) the gradient control along the tubes is not upset by local corona currents or discharges within the column,

c) reduction in tubes over voltages by column to tank breakdown in a region close to the terminal,

d) tube discharges (induced by the beam) are less likely to trigger column local discharges and (possible) column to tank big discharges.

In practice beam quality and tube lifetime should increase. These solutions are now operating at Yale, Rochester and BNL and will be adopted at Munich and Daresbury.

HVEC experiences ( ${ }^{1}$ ) during several test programs have shown that:

a) anyhow a strong connection between tubes and column is very bad (damages on the glass insulators),

b) violence of sparking during the high voltage test, (Heta program) was somehow reduced by the adoption of a second voltage divider.

The resistors will be the so called blue resistors impregnated in blue epoxy with $600 \mathrm{~m} \Omega$ per set (20 elements each set, spark gap every two elements) for the single divider and $1200 \mathrm{M} \Omega$ for the double one.

The charging current to the high voltage terminal will be delivered by two laddertrons running horizontally in the place originally foreseen in the XTU for the belt. A current of $400 \mu \mathrm{A}$ (up charge + down charge) is expected for each laddertron for a total current transported of $800 \mu \mathrm{A}$. The advantages of a Laddertron charging system over a traditional belt are extensively discussed in reference [5].

The version developed at HVEC derivates from the researches developed at Daresbury after the agreement of collaboration between HVEC and the Science Research Council (GB).

The basic difference is that the HVEC version has to run horizontally instead of vertically as at Daresbury.

The HVEC version derivates from the first Daresbury prototype (so called Reading version) with basi-

(1) Prisate communicatıon. cally the same dimensions finally adopted for the NSF: each rung has a length of $190.5 \mathrm{~mm}$, a height of $33.75 \mathrm{~mm}$ and a distance from the next one of $6 \mathrm{~mm}$.

Each rung consists of 2 end sleeves of stainless steel casted (cylindrical shape), a cross tube of aluminium (rectangular shape) and four screws to tighten the different pieces together, the insulating links are done from monocast nylon.

The cross tubes are smaller in height $(<33.75 \mathrm{~mm})$ to avoid that sparking takes places across aluminium easily corroded in $\mathrm{SF}_{6}$ atmosphere.

The final version will be supported in the 3 dead sections by idler pulleys.

A half length section of the Laddertron $(\sim 5.7 \mathrm{~m}$ on the centers) has been operated successfully in mechanical test in atmosphere for more than $2000 \mathrm{~h}$. A full length section ( $\simeq$ double length) has been operated for extra 500 hours. The results indicate that the mechanical concepts of this system-drive pulleys, idler pulleys and chain itself are basically sound. The chain was run at $12 \mathrm{~m} \mathrm{~s}^{-1}$ for most of the time somewhat in excess of expected operating speed of $10 \mathrm{~m} \mathrm{~s}^{-1}$. The installation of this system in MPO is in process. Testing is expected to start around june 1977.

The figure 2 shows a photo of the half length Laddertron assembled at HVEC.

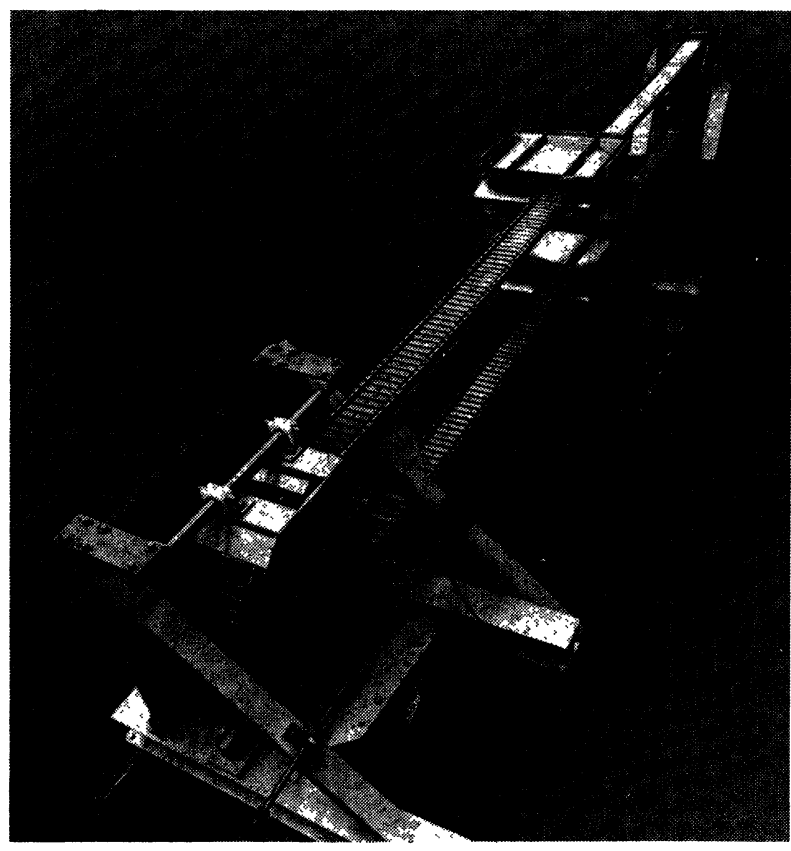

FIG. 2. - Half lenght horizontal ladderton assembled at HVEC during mechanical tests in air.

The analyzing system consists of $90^{\circ}$ analyzing magnet double focusing with a mass energy product $\mathrm{ME} / \mathrm{Z}^{2}=500$. The main characteristics of the magnet are a radius of $80^{\prime \prime}(203 \mathrm{~cm})$ a gap of $1.63^{\prime \prime}(4.14 \mathrm{~cm})$ with a maximum field of $1.6 \mathrm{~T}$. This magnet is rotatable of a $90^{\circ}$ angle around a vertical axis in the orizontal plane by means of an air cushion. By such a rotation the entrance and exit ports can be interchar- 
ged so that practically both $+90^{\circ}$ and $-90^{\circ}$ deflection angles are available. This feature is requested by the planed installation of a superconductive cyclotron as post accelerator.

3. The $150 \mathrm{kV}$ injector. - The injector of the XTU Tandem will be the IONEX 141 OA system built by GIC (Ipswich, Mass. USA) as subcontractor of HVEC. This system is intended to increase the performances and the versatility of the Tandem accelerator by improved matching of the emittance of the injected beam to the admittance of the accelerator ion optical system and by good mass resolution over a large range of ion species.

The schematics of the system (including the configuration adopted for the tests later presented) is shown in figure 3. The whole system can be fully controled remotely or locally.

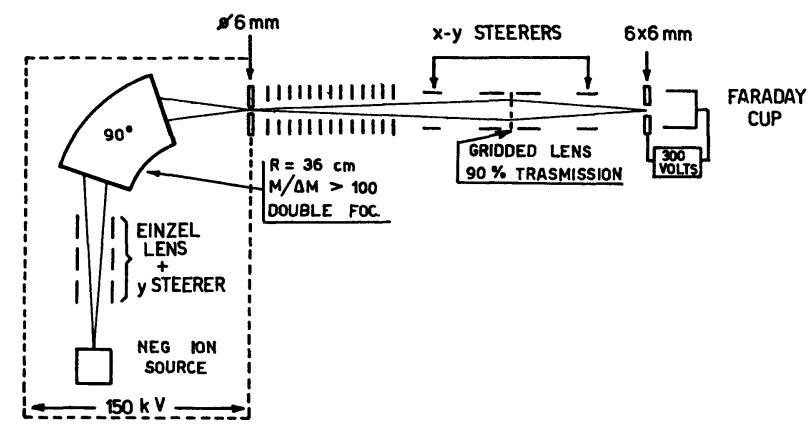

FIG. 3. - Schematic of the $150 \mathrm{kV}$ negative ion injector system adopted also for the tests at GIC plants.

The main feature are the following:

a) optics: The following elements are found in sequence the negative ion beams are extracted by the ion source with $\sim 20 \mathrm{kV}$ voltage. Two power supplies are delivered: $30 \mathrm{kV}-4 \mathrm{~mA}$ (basically for the duoplasmatron source) and $20 \mathrm{kV}-10 \mathrm{~mA}$ (for the sputtering source which needs higher current drain because of the $\mathrm{Cs}$ vapours).

An electrostatic Einzel lens with variable astigmatization is installed to make small corrections to the focal properties of the inflection magnet. The powering of the lens provides also vertical steering of the beam.

The beam is analyzed in a $90^{\circ}$ double focusing deflection magnet with a radius of $14^{\prime \prime}(356 \mathrm{~mm})$ and a gap of $41 \mathrm{~mm}$. The mass energy product is $M E / Z^{2}=9.6$ so that $40 \mathrm{keV}$ ion with $A=240$ can be bent.

The beam is accelerated to ground potential by an injection voltage up to $150 \mathrm{kV}(3 \varnothing$ insolation transformer $150 \mathrm{kV}$ and $150 \mathrm{kV}$ power supply).

A gridded lens located after the acceleration tube produce a waist at the entrance of the Tandem. Steering in $X$ and $Y$ directions is provided before an after the gridded lens.

b) Vacuum and cooling: The vacuum $<10^{-5}$ torr (according to the ion source used) is provided by two oil diffusion pumps with a freon refrigerated baffle. A
4 " pumps is located before the acceleration tube and a larger one 6" near the ion source the handle the gas load coming from the ion source.

The two pumps operating in parallel provide pumping speeds, after the baffles of $\sim 300$ and $7001 / \mathrm{s}$ respectively. One closed circuit with freon and one with demineralized water are supplied.

A photo of the injector is shown in figure 4.

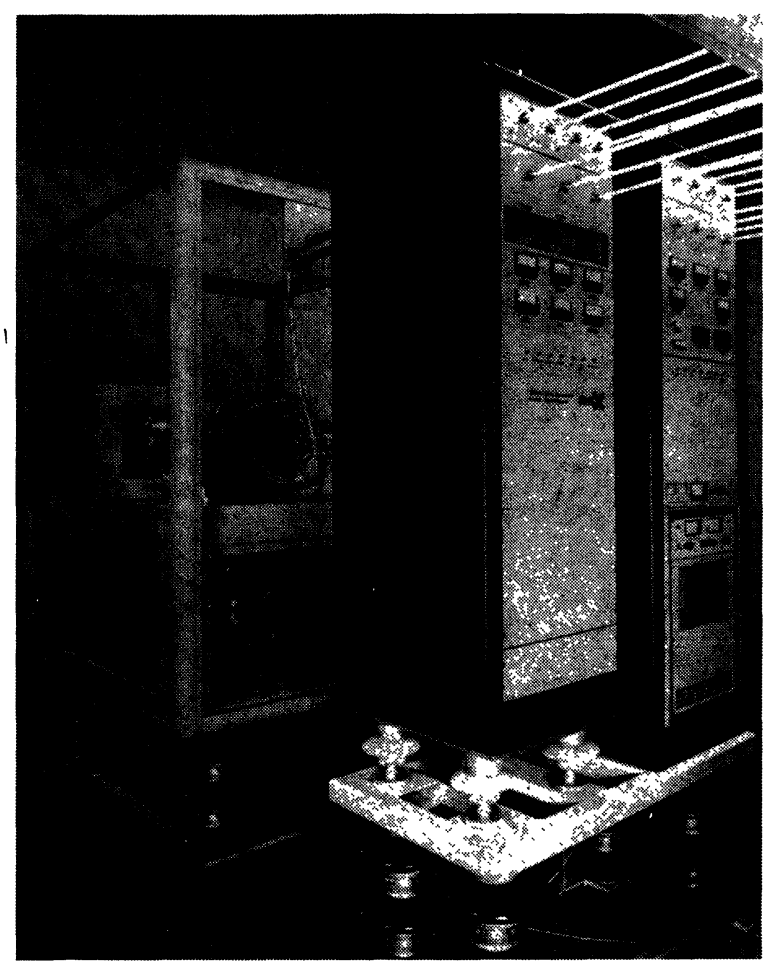

FIG. 4. - Photo of the injector.

3.1. TEST. - The injector includes also three negative ion sources:

a) - off axis duoplasmatron,

b) - duoplasmatron with exchange channel,

c) - sputter.

The whole system, including the 3 ion sources, was successfully tested during 1 week period at GIC plants by INFN and GIC people together.

The operation of the whole system turned out to be very reliable, except for some small minor troubles. In particular with $6 \mathrm{~mm} \varnothing$ exit slits the mass resolution turned out to be $M / \Delta M>100$ (well above the specification guaranteed $M / \Delta M>60$ ).

A typical spectrum taken with a mixed $\mathrm{Ni}+\mathrm{Cu}$ come on the sputtering source is shown in figure 5 .

The test data on the three ion sources are shown in table II.

Figure 6 shows the data about $\mathrm{Ca}$ beam abtained with a spray of $\mathrm{NH}_{3}$ according to the results of Middleton [6] and Korschinek et al [7].

In this case the vacuum reading was $\sim 2 \times 10^{-5}$ Torr. 


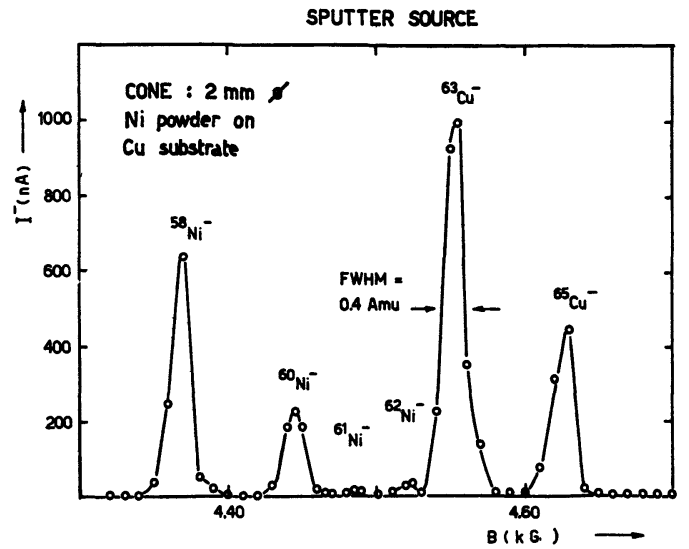

FIG. 5. - Negative ions extracted by the sputtering source with a mixed $\mathrm{Cu}-\mathrm{Ni}$ cone. The mass resolution is better than $1: 100$.

TABLE II

Negative ion source tests

\begin{tabular}{|c|c|r|c|}
\hline & & \multicolumn{2}{|c|}{ Current } \\
\cline { 3 - 4 } Source & Beam & measured & guaranteed \\
\hline $\begin{array}{c}\text { Duoplas- } \\
\text { matron } \\
\text { off-axis }\end{array}$ & & & \\
& & & \\
& $\mathrm{H}^{-}$ & $50 \mu \mathrm{A}$ & - \\
\hline & $12 \mathrm{C}^{-}$ & $45 \mu \mathrm{A}$ & - \\
& $28 \mathrm{Si}^{-}$ & $7 \mu \mathrm{A}$ & - \\
& $63 \mathrm{Cu}^{-}$ & $1.6 \mu \mathrm{A}$ & $2.0 \mu \mathrm{A}, \mathrm{Cu}^{-}$ \\
& $65 \mathrm{Cu}^{-}$ & $0.6 \mu \mathrm{A}$ & \\
Sputtering & $58 \mathrm{Ni}^{-}$ & $2.3 \mu \mathrm{A}$ & $3.0 \mu \mathrm{A}, \mathrm{Ni}^{-}$ \\
& $60 \mathrm{Ni}^{-}$ & $0.8 \mu \mathrm{A}$ & \\
& $56 \mathrm{Fe}^{-}$ & $220 \mathrm{nA}$ & $200 \mathrm{nA}, \mathrm{Fe}^{-}$ \\
& $54 \mathrm{Fe}^{-}$ & $13 \mathrm{nA}$ & \\
& $40 \mathrm{CaH}^{-}$ & $440 \mathrm{nA}$ & $200 \mathrm{nA}, \mathrm{Ca}^{-}$ \\
& $48 \mathrm{TiH}^{-}$ & $230 \mathrm{nA}$ & $200 \mathrm{nA}, \mathrm{Ti}^{-}$ \\
& $51 \mathrm{~V}^{-}$ & $220 \mathrm{nA}$ & $200 \mathrm{nA}$ \\
\hline Duoplas- & & & \\
matron & ${ }^{7} \mathrm{Li}^{-}$ & $3 \mu \mathrm{A}$ & $2 \mu \mathrm{A}$ \\
+ lithium & $6 \mathrm{Li}^{-}$ & $0.3 \mu \mathrm{A}$ & \\
channel & ${ }^{4} \mathrm{He}^{-}$ & $7.3 \mu \mathrm{A}$ & $4 \mu \mathrm{A}$ \\
\hline
\end{tabular}

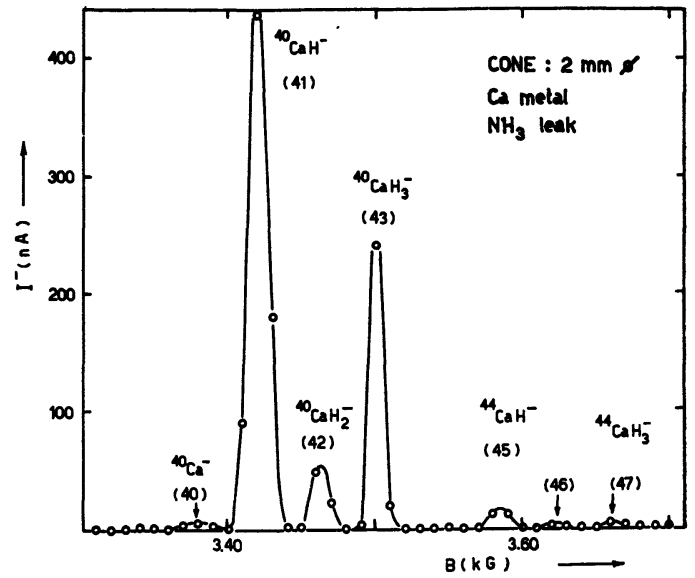

FIG. 6. - Test data of $\mathrm{Ca}$ beam with the sputtering source.
4. Building and auxiliary equipments. - The new accelerator building will be located near the already existing $\mathrm{CN}$ Van de Graaff laboratory as indicated in figure 7.

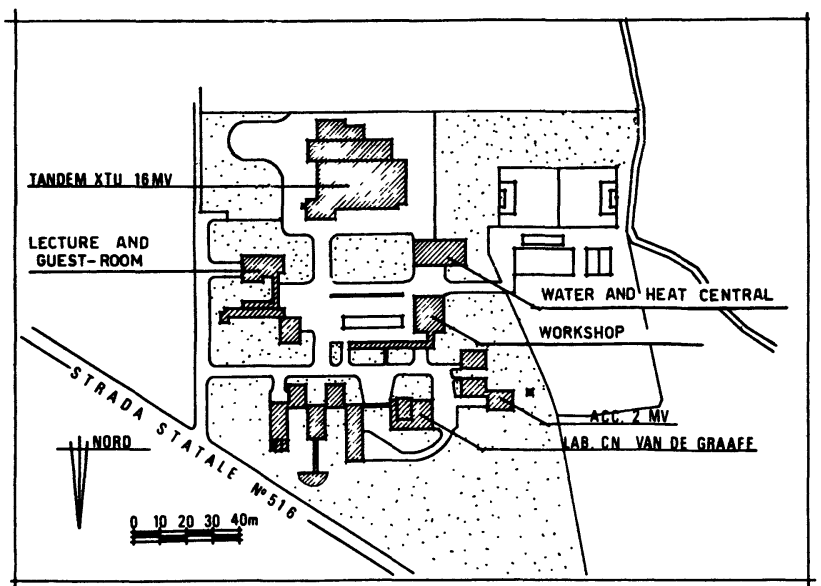

FIG. 7. - Planimetry of the LNL laboratory.

The present consideration is to have beyond the accelerator vault a large target area and a large experimental area, this last one devoted also to the Tandem control and to the computing facility. The building will house also some offices and laboratory only for the basic operation and servicing of the machine and preparation of the experiments, since a comprehensive workshop organization already exists within the laboratory.

The general layout of the building is seen in figure 8 .

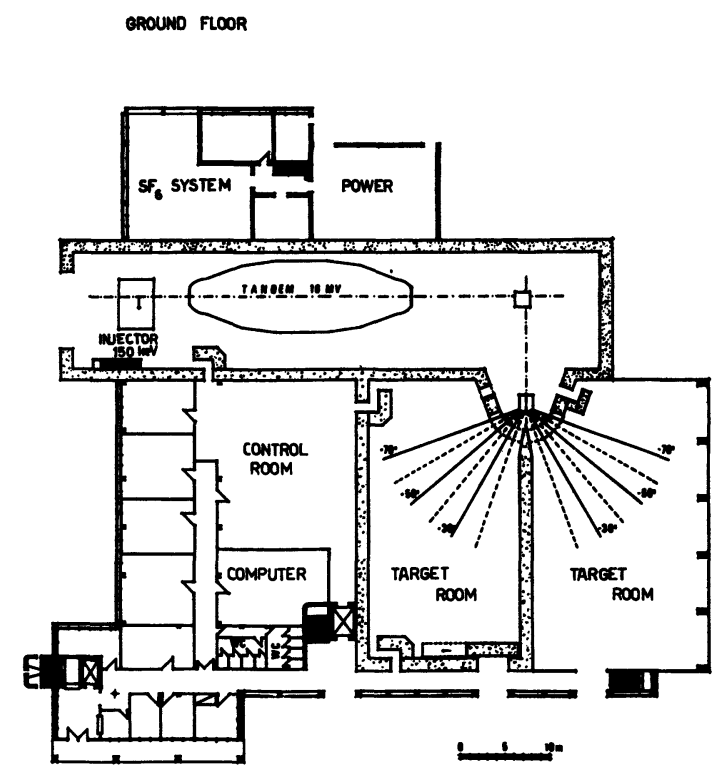

Fig. 8. - Gound floor plan to the XTU - Tandem building.

The main characteristics are the following:

- The accelerator room has dimensions $13 \mathrm{~m} \times 59.2 \times 10.5 \mathrm{~m}$ (height), the floor is foreseen for a specific weight of $2 \mathrm{t} / \mathrm{m}^{2}$, the walls thickness is $1.5 \mathrm{~m}$ and the ceiling $0.9 \mathrm{~m}$ of reinforced concrete. 
- The room is equiped with an overhead crane with a $10 \mathrm{t}$ hoist.

- On the side of the accelerator there are the rooms for the $\mathrm{SF}_{6}$ recovery system and for the main power transformers located all at ground level.

The target area fulfil the following purposes:

a) Two rooms completely screened from each other so that they can work in a ping-pong basis; i.e. in one room experiments can be prepared while the other one is used for the measurements. Both rooms have an overhead crane with a $\sim 10 \mathrm{t}$ hoist which can service practically each point of the floor.

b) One room (dimension $16 \mathrm{~m} \times 30.5 \mathrm{~m} \times 7 \mathrm{~m}$ ) is heavily shielded (some wall and ceiling thickness as the Tandem vault) for hot beams, mainly protons, deuterons, where high dosis of radiations can be expected.

c) One room (dimensions $19 \mathrm{~m} \times 32 \mathrm{~m} \times 11.6 \mathrm{~m}$ ) has no permanent heavy shielding and will be used for heavy ion beams and for time of flight measurements.

The floors are foreseen for a specific weight of $10 \mathrm{t} / \mathrm{m}^{2}$ except the part of the non shielded room next to the Tandem were a specific weight of $20 \mathrm{t} / \mathrm{m}^{2}$ is foreseen for the possible installation of a magnetic spectrograph.

The control room, is $12.6 \mathrm{~m} \times 32.4 \mathrm{~m} \times 3.60 \mathrm{~m}$ (height) has a floating floor and will be divided in three sections, one for the control of the machine, on for the control of the experiments and one for the online computer facility.

A cellar will run under the accelerator, target and control rooms.

4.1. BEAM TRANSPORT. - The beam transport from the exit of the $90^{\circ}$ magnet to the targets is quite conventional and consists in a large switching plus quadrupoles as schematically indicated in figure 9.

The whole system will be constructed by Danfysik (Jyllinge Danmark).

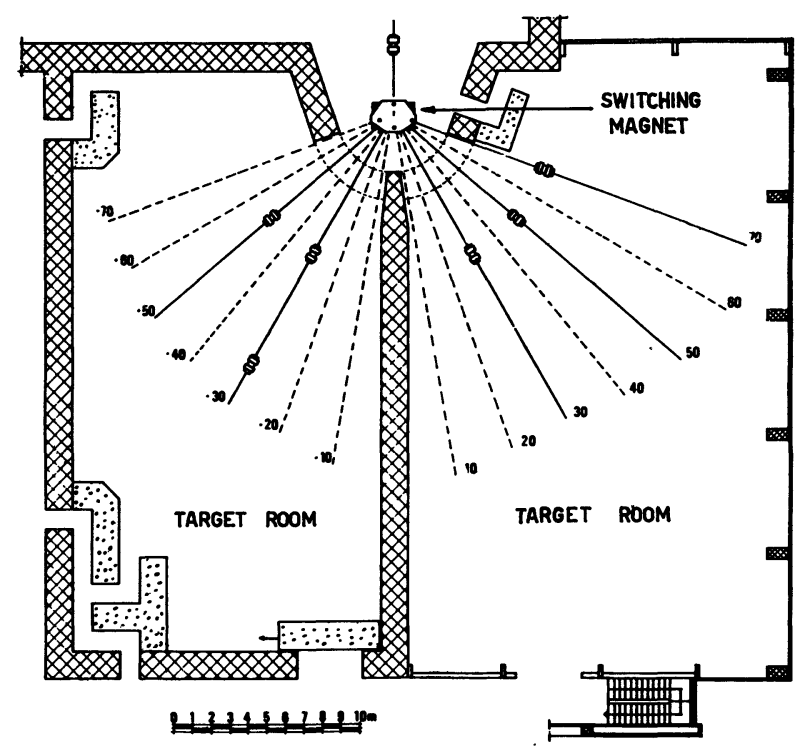

FIG. 9. - Lay out of the beam transport system.
The characteristics of the system are the followings:

a) Switching magnet: of semicircular type pole gap $50 \mathrm{~mm}$, maximum field $1.6 \mathrm{~T}$.

The following deflection angles are possible: $\pm 70^{\circ}, \pm 60^{\circ}, \pm 50^{\circ}, \pm 40^{\circ}, \pm 30^{\circ}, \pm 20^{\circ}, \pm 10^{\circ}$ with a mass energy product of $120,155,335,585,1310$, 5190 respectively. The power supply of $37 \mathrm{~kW}$ can be controlled analogically and digitally.

b) Quadrupole doublets: are all identical, inclusive the one placed before the switching magnet.

They have an aperture of $100 \mathrm{~mm}$ diameter, max gradient of $1.2 \mathrm{kGauss} \mathrm{cm}^{-1}$, effective length of $300 \mathrm{~mm}$ and a separation of $150 \mathrm{~mm}$.

The optical characteristics are such that they can produce a stigmatic image at $5 \mathrm{~m}$ from the exit for an object at $5 \mathrm{~m}$ from the entrance for a maximum magnetic rigidity $B \rho=3.3 \mathrm{~T} . \mathrm{m}$. With these quadrupoles one can have, as schematized in figure 9, short channels $\sim 12-14 \mathrm{~m}$ long with one lens and long channels 20-24 m long with two lenses.

Practically the whole system from $\pm 10^{\circ}$ up to $\pm 30^{\circ}$ can handle beams with $B \rho=3.3$ which is the rigidity of the beam produced also by the superconductive cyclotron.

5. The superconductive cyclotron booster. - In connection with this XTU-Tandem project the Milano group of INFN leader by F. Resmini has studied and proposed the construction of a superconductive cyclotron to be used essentially as booster of the Tandem.

The ions from the Tandem are injected along a

TABLE III

\section{Parameters of the superconductive cyclotron}

max. energy $\quad 55 \mathrm{MeV} / \mathrm{Nucl} . \rightarrow 10 \mathrm{MeV} / \mathrm{Nucl}$. min. energy $1 / 4$ of max. energy

$K=M E / Z^{2}=500$

$0.1 \%<\Delta E / E<0.2 \%$

Emittance $(A): 4 \mathrm{~mm}$.mrad. $<A<6 \mathrm{~mm}$. mrad. if $A_{\text {Tandem }}<15 \mathrm{~mm}$. mrad.

Current: $10^{11}-10^{12}$ particles s ${ }^{-1}$

if the Tandem delivers $10^{12}-10^{13}$ particles $\mathrm{s}^{-1}$

\section{Construction data}

POLE DIA: $1.8 \mathrm{~m}$

$22 \mathrm{kG}<\mathrm{B}<41 \mathrm{kG}$ (3 sectors - spiral shape).

Acceleration Dees: 3 with $100 \mathrm{kV}$ peak voltage.

Deflection: electrostatic 120 or $140 \mathrm{kV} \mathrm{cm}{ }^{-1}$.

Bunching of the beam injected into the cyclotron before.

Tandem at $400-500 \mathrm{kV}$ level with two cavities.

Frequency 21 or $63 \mathrm{MHz}$

$\Delta \varphi \quad \pm 1.5^{\circ}$ or $\pm 3^{\circ}$

Efficiency $\quad 35 \%$ or $60 \%$

after Tandem electrostatic chopper operating on a frequency locked to cyclotron frequency. 
circular path around the middle of the cyclotron, stripped (in this way their magnetic rigidity in strongly reduced so that they are placed in a much smaller circular orbit) and then accelerated as usual by the radiofrequency.

The superconductive field reduces strongly the dimensions of the Cyclotron and consequently also the cost (even if a liquid helium cryostat has to be installed).

In this way the Tandem of the two machines would constitute one of the largest nuclear physics facility.

The project has for the moment got founds for a model (model cyclotron $1: 6$; model RF cavity $1: 1$ ).

The measurements on the model, in particular the mapping of the superconductive magnetic field, will help also to fix the definitive parameters of the machine.

The location of the cyclotron with respect to the Tandem is indicated in figure 10 . The beam is bent by the rotatable $90^{\circ}$ magnet in the direction apposet to that of the switching magnet, injected in the cyclotron, extracted at an angle of $\sim 180^{\circ}$ to the injection direction, and then brought back into the beam transport system between the $90^{\circ}$ and the switching magnet. In this way all the experimental facilities will be used also for the combination of the two machines.

6. Time schedule. - Time schedule in always a very crucial and delicate points because very often it happens that delays appear even when everything is carefully planed.

For the moment we are considering the following schedule.

The physical construction of the building will start

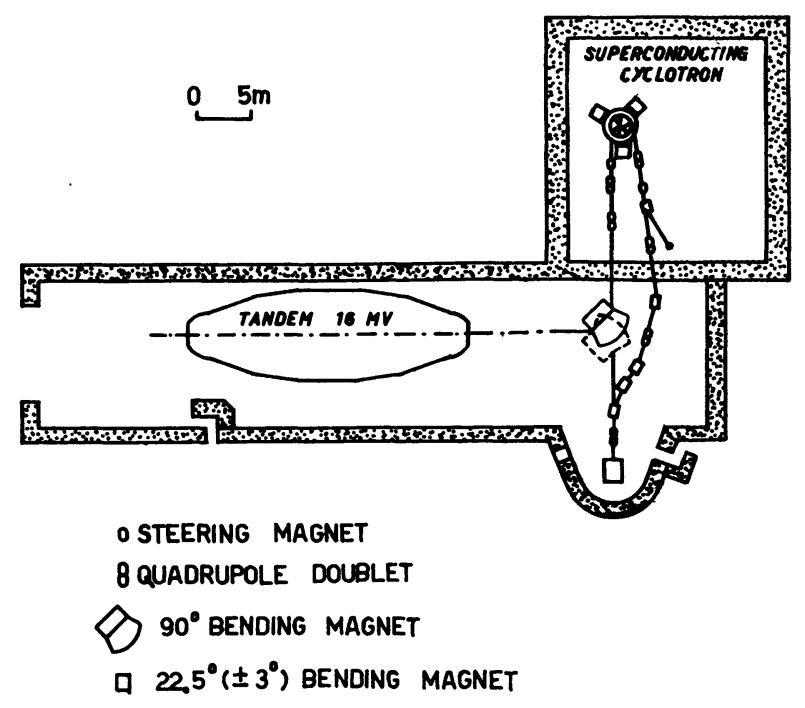

FIG. 10. - Proposed position of the superconductive cyclotron with respect to the XTU - Tandem.

in june 1977 and after one year the tank will be in situ so that the mounting of the machine (to be shipped early in 1978 by HVEC) will start.

After one year it is expected that the acceptance tests will start so that sometimes between end 1979 and beginning of 1980 the experiments should start.

Acknowledgements. - The author of this talk want to acknowledge all the colleagues physicists and technicians of LNL for the help in the preparation of the manuscript in particular R.A. Ricci responsible of the project.

The deep collaboration of HVEC and GIC is also greatefully acknowledged.

References

[1] Filosofo I., Kusstatscher P., Poiani G., Ricci R. A., RosTAGNI A. and VILLI C., Report INFN, 22/3/1966.

[2] Filosofo I., Kusstatscher P., Morando M., Ricci R. A. and SigNORINI C., Report INFN, 15/5/1974.

[3] Goldie C. H. and Trump J. G., Nucl. Instrum. Methods 122 (1974) 277 and HVEC, Science Division, Newsletter august 1973.
[4] Purser K. H., Gove H. E., Lund T. S. and Mc K.HyDER H. R., Nucl. Instrum. Methods 122 (1974) 159.

[5] Aitken T. W., Charlesworth T. R., Daresbury Laboratory Report DL/NSF/TM 13.

[6] Middleton R., Nucl. Instrum. Methods submitted for publication.

[7] KorsChineK G. and Kutschera W., Nucl. Instrum. Methods submitted for publication. 